\title{
A CASE SERIES ON EPISTAXIS IN PATIENTS ATTENDING ENT OPD, GGH, KAKINADA
}

\author{
Ravula Bhimeswar1, Vuppu Chandra Venkata Siva Kumar², Padavala Koteswar Rao ${ }^{3}$, Dasari Siva Sankaraih", Ijju Hemanth ${ }^{5}$ \\ ${ }_{1}^{1}$ Associate Professor, Department of ENT, Rangaraya Medical College, Kakinada, Andhra Pradesh, India. \\ ${ }^{2}$ Assistant Professor, Department of ENT, Rangaraya Medical College, Kakinada, Andhra Pradesh, India. \\ ${ }^{3}$ Assistant Professor, Department of ENT, Rangaraya Medical College, Kakinada, Andhra Pradesh, India. \\ 4Junior Resident, Department of ENT, Rangaraya Medical College, Kakinada, Andhra Pradesh, India. \\ 5Junior Resident, Department of ENT, Rangaraya Medical College, Kakinada, Andhra Pradesh, India.
}

\section{BACKGROUND} ABSTRACT

Epistaxis is extremely a common condition ${ }^{[1]}$ and affects all age groups. 5 to $10 \%$ of the population experiences an episode of epistaxis each year. The frequency of epistaxis is difficult to determine, because most episodes resolve with self-treatment and therefore are not reported.[2] More than 90\% of bleeds occur anteriorly and arise from Little's area, where the Kiesselbach's plexus forms on the septum. ${ }^{[3][4]}$ Most nose bleeds stop without treatment. For most of the general population epistaxis is a nuisance. However, the problem can be life-threatening, especially in elderly patients and in those with underlying medical problems. We evaluated 50 patients presenting with complaints of bleeding from nose and studied in detail.

\section{MATERIALS AND METHODS}

This is a case series carried out in the Dept. of ENT, Govt. General Hospital, Rangaraya Medical College, Kakinada between December 2015 and September 2017. The study was approved by the ethics committee of the institution.

\section{RESULTS}

20 - 40 years' age groups are the most commonly affected. Among the aetiologies, idiopathic is the most common cause (22\%). Most common site of bleeding is anterior part; therefore, anterior nasal packing was done for majority of the cases.

\section{CONCLUSION}

From the present study we come to the conclusion that epistaxis is a problem seen in all age groups, more so in the adolescents and young adults, and that males are affected more than females. The cause of epistaxis was not known, i.e. idiopathic in the majority of cases. When the cause of epistaxis is present, it is found that trauma is the most common cause in the younger patients, while in older patients the most common cause is epistaxis secondary to hypertension. The anterior nasal septum and more so the Little's area is the commonest site of bleeding.

\section{KEY WORDS}

Juvenile Nasopharyngeal Angiofibroma, Inverted Papilloma, Rhinosporidiosis, Hypertension.

HOW TO CITE THIS ARTICLE: Bhimeswar R, Kumar VCVS, Rao PK, et al. A case series on epistaxis in patients attending ENT OPD, GGH, Kakinada. J. Evolution Med. Dent. Sci. 2018;7(22):2660-2663, DOI: 10.14260/jemds/2018/598

\section{BACKGROUND}

Epistaxis is extremely a common condition and affects all age groups. 5 to $10 \%$ of the population experiences an episode of epistaxis each year. Most nose bleeds stop without treatment. For most of the general population epistaxis is a nuisance. However, the problem can be life-threatening, especially in elderly patients and in those with underlying medical problems. We evaluated 50 patients presenting with complaints of bleeding from nose and studied in detail.

\section{Aims and Objectives}

To find out various aetiological factors of epistaxis in various age groups attending ENT OPD, Rangaraya Medical College, GGH Kakinada and to determine the role of endoscopy in localising the bleeding point immediately or after acute management.

'Financial or Other Competing Interest': None.

Submission 29-01-2018, Peer Review 27-03-2018,

Acceptance 05-03-2018, Published 28-05-2018.

Corresponding Author:

Dr. Vuppu Chandra Venkata Siva Kumar,

D. No. 70-17A-14/H,

Soujanya Nagar,

RTO Office Road, Kakinada, India

E-mail: drshivaent@gmail.com

DOI: $10.14260 /$ jemds $/ 2018 / 598$

\section{(c) $(1) \risingdotseq$}

\section{MATERIALS AND METHODS}

\section{Inclusion Criteria}

In the study 50 patients attending the ENT Department of Government General Hospital, Rangaraya Medical College, Kakinada between December 2015 and September 2017, with complaints of bleeding from nose (Epistaxis) have been included.

\section{Method of Collection of Data}

This is a case series carried out in the Dept. of ENT, Govt. General Hospital, Rangaraya Medical College, Kakinada between December 2015 and September 2017. The study was approved by the ethics committee of the institution. All patient's detailed history was taken so as to rule out systemic, hereditary causes for epistaxis. A detailed systemic and local examination was done to find an aetiological factor for epistaxis.

Relevant investigations which included a complete haemogram, renal profile, coagulation profile, complete urine examination, radiology (CT and x-ray) of the PNS, nasopharynx and chest, ECG, FNAC- fine needle aspiration cytology and biopsy were done. Patients requiring a surgical procedure or in whom bleeding was profuse enough to introduce anterior or posterior nasal packing were admitted in the ENT Department of Government General Hospital, 
Rangaraya Medical College, Kakinada. Regular follow-up to rule out recurrence and ensure cure was done. The following variables were analysed: Age, sex, aetiology, bleeding site and method of treatment.

\section{RESULTS}

In the present study, 50 cases of epistaxis were studied during the period from December 2015 to September 2017 at the ENT Department of Rangaraya Medical College, Government General Hospital, Kakinada. This study shows the following observations:

\begin{tabular}{|c|c|c|c|}
\hline Age & Male & Female & Total \\
\hline $0-9$ & 2 & 1 & 3 \\
\hline $10-19$ & 4 & 1 & 5 \\
\hline $20-29$ & 9 & 2 & 11 \\
\hline $30-39$ & 10 & 3 & 13 \\
\hline $40-49$ & 5 & - & 5 \\
\hline $50-59$ & 3 & 2 & 5 \\
\hline $60-69$ & 3 & 1 & 4 \\
\hline $70-79$ & 1 & 2 & 3 \\
\hline 80 and above & 1 & - & 1 \\
\hline Total & $\mathbf{3 8}$ & $\mathbf{1 2}$ & $\mathbf{5 0}$ \\
\hline \multicolumn{5}{|c}{ Table 1. Age and Sex Variation of Cases } \\
\hline
\end{tabular}

\begin{tabular}{|c|c|c|}
\hline Aetiology & No. of Cases & Percentage \\
\hline Traumatic & 8 & 16.0 \\
\hline Hypertension & 6 & 12.0 \\
\hline Rhinosporidiosis & 1 & 2.0 \\
\hline Angiofibroma & 4 & 8.0 \\
\hline Foreign body nose & 5 & 10.0 \\
\hline Idiopathic & 11 & 22.0 \\
\hline Haemangioma septum & 3 & 6.0 \\
\hline Inverted papilloma & 2 & 4.0 \\
\hline Nasal mass & 2 & 4.0 \\
\hline Blood dyscrasias & 3 & 6.0 \\
\hline Secondary to DNS & 3 & 6.0 \\
\hline Rhinolith & 2 & 4.0 \\
\hline Total & 50 & 100.0 \\
\hline \multicolumn{3}{|c|}{$\begin{array}{c}\text { Table 2. Aetiology among } 50 \text { Cases of Present } \\
\text { Study }\end{array}$} \\
\hline
\end{tabular}

\begin{tabular}{|c|c|c|}
\hline Bleeding Site & No. of Patients & Percentage \\
\hline Anterior & 28 & $56 \%$ \\
\hline Vestibule & - & - \\
\hline Anterior septum & 10 & $20 \%$ \\
\hline Lateral wall & 2 & $4 \%$ \\
\hline Little's area & 12 & $24 \%$ \\
\hline Anterior floor & 4 & $8 \%$ \\
\hline Posterior & 2 & $4 \%$ \\
\hline Posterior septum & - & - \\
\hline Posterior lateral wall & 2 & $4 \%$ \\
\hline Undetermined & 18 & $36 \%$ \\
\hline Nasopharynx & 2 & $4 \%$ \\
\hline Paranasal sinuses & - & - \\
\hline Total & 50 & $100 \%$ \\
\hline
\end{tabular}

\begin{tabular}{|c|c|c|}
\hline Method of Treatment & No. of Cases & \% \\
\hline Anterior nasal packing & 28 & $56 \%$ \\
\hline $\begin{array}{c}\text { Posterior nasal packing } \\
\begin{array}{c}\text { DNE followed by removal of foreign } \\
\text { body }\end{array}\end{array}$ & 2 & $4 \%$ \\
\hline Correction of fracture nasal bone & 2 & $10 \%$ \\
\hline
\end{tabular}

\begin{tabular}{|c|c|c|}
\hline $\begin{array}{l}\text { Endoscopic removal } \\
\text { of Nasal Mass }\end{array}$ & 3 & $6 \%$ \\
\hline $\begin{array}{c}\text { Combined approach } \\
\text { (Endoscopic and Right Medial } \\
\text { Maxillectomy) excision of } \\
\text { Angiofibroma }\end{array}$ & 1 & $2 \%$ \\
\hline $\begin{array}{l}\text { Endoscopic removal } \\
\text { of Rhinolith }\end{array}$ & 2 & $4 \%$ \\
\hline Laser excision of Haemangioma & 3 & $6 \%$ \\
\hline Septoplasty with excision of spur & 3 & $6 \%$ \\
\hline DNE followed by Electric Cauterisation & 1 & $2 \%$ \\
\hline \begin{tabular}{|c|} 
Total \\
\end{tabular} & 50 & $100 \%$ \\
\hline
\end{tabular}

\section{Individual Case Reports}

\section{Juvenile Nasopharyngeal Angiofibroma}

A 20-year-old male patient presented with intermittent bleeding from both nasal cavities since 1 month, associated with change in voice, nasal block since 1 month, snoring since 1 month, on examination a smooth greyish-pink mass extending into the oropharynx was found, slight trickle of blood present on the posterior pharyngeal wall, anterior rhinoscopy was normal, post rhinoscopy revealed a greyishpink mass in the nasopharynx which was extending into the oropharynx. CT scan showed large enhancing soft tissue mass seen in nasopharynx extending into oropharynx for which combined approach (endoscopic + medial maxillectomy) excision of tumour under GA was done and mass was delivered through oral cavity. Postop follow-up was done for 2 years and the patient has no recurrence.
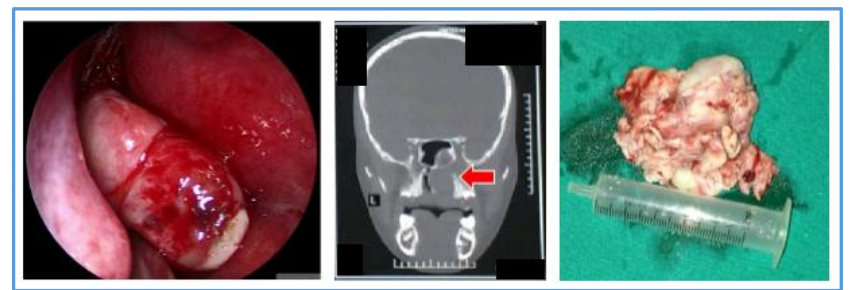

\section{Rhinosporidiosis}

A 21-year-old male hailing from Srikakulam, Andhra Pradesh presented with bleeding from left nasal cavity. On examination a mass lesion is identified in the left nasal cavity. On endoscopic examination, the mass resembled Rhinosporidiosis. Endoscopic excision with cauterisation of the base from floor of nasal cavity and nasopharynx was done. Larynx was inspected for lesions and none were found. He was put on Dapsone for a period of 3 months postoperatively. He is on follow-up for 10 months with no recurrence.

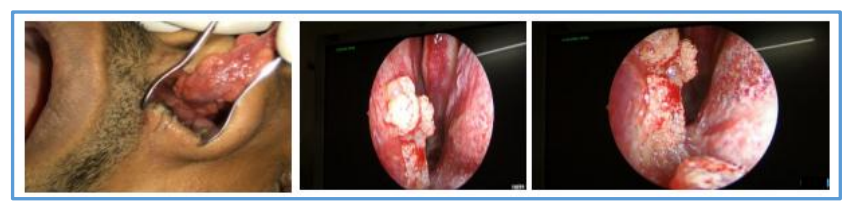

3. A 45-year-old male patient presented with bleeding from right nasal cavity. CT scan PNS showed soft tissue attenuation in right side ethmoidal and right maxillary sinus s/o inverted papilloma. Endoscopic excision under GA was done and specimen is sent for HPE. 
HPE concluded the diagnosis of inverted papilloma. The patient is on follow-up for 1.5 years after surgery without any recurrence.

4. A 4-year-old male child presented to the OPD with complaint of left nasal bleeding since 1 week with h/o insertion of Foreign Body 1 week back. On examination, Foreign Body (tamarind seed) was seen in left nostril DNE and Foreign Body (tamarind seed) removal under GA was done.

\section{Hypertensive Epistaxis}

A 52-year-male patient presented to our casualty with right nasal bleeding since 1 day. No history of trauma was present. On examination, there was deviated nasal septum towards right and active bleeding was present from the right nasal cavity. His blood pressure was $160 / 90 \mathrm{mmHg}$ in supine position at the time of presentation. Posterior nasal packing was done immediately and the bleeding subsided. Later the patient was investigated. Complete blood picture, bleeding time, clotting time, PT, APTT, INR and LFTs were normal. DNE was done later and it was normal. The patient was prescribed anti-hypertensives and follow-up was done for 6 months. There was no recurrence.

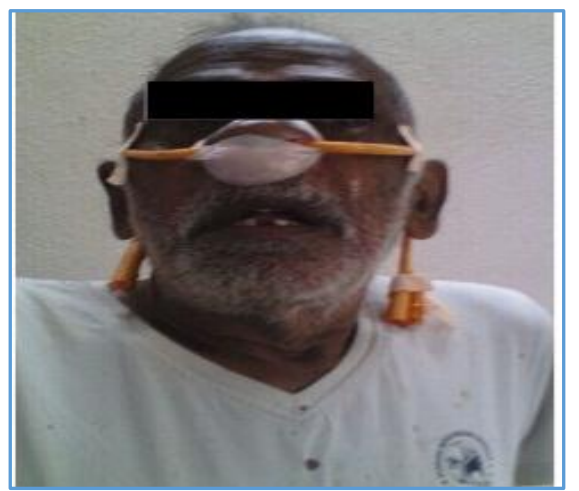

\section{Hemangiopericytoma}

A 40-year-old male patient presented with nasal obstruction and epistaxis since 1 month. On nasal endoscopy, a pink fleshy mass was found and was bleeding on touch. Biopsy (done at a different centre) revealed hemangiopericytoma. CECT showed enhancing areas in left nasal cavity without evidence of bone destruction. Endoscopic excision was done with blood loss of around $200 \mathrm{~mL}$. Bleeding was controlled by suction cautery and nasal packing. The excised specimen was sent for HPE, which revealed Hemangiopericytoma. Patient underwent radiotherapy and has been disease free for 1.5 years.

\section{DISCUSSION}

Juvenile Nasopharyngeal Angiofibroma (JNA) is a rare benign tumour arising predominantly in the nasopharynx of adolescent males. Hormonal theory is suggested due to its occurrence in adolescent males.[5] It is an aggressive neoplasm and shows a propensity for destructive local spread often extending to the base of the skull and into the cranium. Clinically, however, it is obscure with painless, progressive unilateral nasal obstruction being the common presenting symptom with or without epistaxis and rhinorrhoea. Diagnosis of JNA is made by complete history, clinical examination, radiography, nasal endoscopy and by using specialised imaging techniques such as arteriography, computed tomography and magnetic resonance imaging. Histopathology reveals a fibrocellular stroma with spindle cells and haphazard arrangement of collagen interspersed with an irregular vascular pattern. A case report of JNA, which was extending into the Oropharynx was found for which excision of tumour under General Anaesthesia was done.

The mucosal lining of nose and paranasal sinuses is known as Schneiderian membrane. Papillomas arising from this membrane is very unique, in that they are found to be growing inwardly and hence the term inverted papilloma. Inverted papillomas behave like neoplasms, arising from reserve/ replacement cells located at the basement membrane of the mucosa. The resulting thickening of the epithelium assumes an inverting, fungiform or combination growth pattern. Depending on the degree of metaplasia, varying amounts of respiratory/ cylindrical cells may be seen in Schneiderian papilloma. Rarely, the papilloma may be composed entirely of cylindrical cells and hence the term cylindrical cell papilloma is used to describe this subtype.

As road traffic accidents are increasing now a days, we are getting more cases of epistaxis due to road traffic accidents apart from digital trauma in children.

Rhinosporidiosis is an infection caused by Rhinosporidium seeberi. Rhinosporidiosis has been associated with rural residence, occupation in farming or agriculture, and bathing in ponds or rivers.[6][7][8] The floor of the nose and inferior turbinate are the most common sites.

A hemangiopericytoma (HPC) is a type of soft tissue sarcoma that originates in the pericytes in the walls of capillaries. The term hemangiopericytoma (HPC) was first used by Stout and Murray in 1942 to describe a distinct neoplasm of pericytic origin.[9] When inside the nervous system, although not strictly a meningioma tumour, it is a meningeal tumour with a special aggressive behaviour.[10]

Recurrent unilateral epistaxis should particularly raise concern for neoplasm.[11] Recurrent episodes of epistaxis, even if self-limited should raise suspicion for significant nasal pathology.[12]

The incidence of epistaxis is bimodal, peaking at ages younger than 10 years and older than 50 years and it appears to be more common in males.[13]

\section{CONCLUSION}

From the present study we come to the conclusion that epistaxis is a problem seen in all age groups, more so in the adolescents and young adults, and that males are affected more than females.

The cause of epistaxis was not known, i.e. idiopathic in the majority of cases. When the cause of epistaxis is present it is found that trauma is the most common cause in the younger patients, while in older patients the most common cause is epistaxis secondary to hypertension.

The anterior nasal septum and more so the Little's area is the commonest site of bleeding. The Kiesselbach's plexus or Little's area is an anastomotic network of vessels located on the anterior cartilaginous septum. It receives blood supply from both the ICA and the ECA. The site of bleeding was undetermined in a large majority of patients even after the use of the endoscope. 
Anterior nasal packing was the most common procedure of treatment in our study.

Posterior nasal packing was the procedure used in older people secondary to hypertension.

Surgical endoscopic cautery can be used to control the bleeding in cases of idiopathic epistaxis, if the bleeding point is visualised.[14] This modality of treatment causes less discomfort to the patient and less hospital stay.

We should manage a case of epistaxis in an orderly manner and every effort should be made to find out the cause before deciding to go to the next modality of management.

\section{REFERENCES}

[1] Traboulsi H, Alam E, Hadi U. Changing trends in the management of epistaxis. Article ID 263987, Int J Otolaryngol 2015;2015: p. 7.

[2] Gifford TO, Orlandi RR. Epistaxis. Otolaryngol Clin North Am 2008;41(3):525-36, viii.

[3] Guarisco JL, Graham HD. Epistaxis in children: causes, diagnosis and treatment. Ear Nose Throat J 1989;68(7):522, 528-30, 532 passim.

[4] Padgham N. Epistaxis: anatomical and clinical correlates. J Laryngol Otol 1990;104(4):308-11.

[5] Liu Z, Wang J, Wang H, et al. Hormonal receptors and vascular endothelial growth factor in juvenile nasopharyngeal angiofibroma: immunohistochemical and tissue microarray analysis. Acta Otolaryngol 2015;135(1):51-7.
[6] Karthikeyan P, Vijayasundaram S, Pulimoottil DT. A retrospective epidemiological study of rhinosporidiosis in a rural teritiary care centre in Pondicherry. J Clin Diagn Res 2016;10(5):MC04-8.

[7] Almeida FA, de Moura FL, Pinho JD, et al. Rhinosporidiosis: the largest case series in Brazil. Rev Soc Bras Med Trop 2016;49(4):473-6.

[8] Dutta S, Haldar D, Dutta M, et al. Socio-demographic correlates of rhinosporidiosis: a hospital-based epidemiologic study in Purulia, India. Indian J Otolaryngol Head Neck Surg 2017;69(1):108-12.

[9] Stout AP, Murray MR. Hemangiopericytoma: a vascular tumor featuring zimmermann's pericytes. Ann Surg 1942;116(1):26-33.

[10] Greenberg M. Handbook of Neurosurgery. 7th edn. New York: Thieme 2010.

[11] Cummings CW. Epistaxis. Chap-40. Cummings otolaryngology: head and neck surgery. $4^{\text {th }}$ edn. Philadelphia, PA: Elsevier Mosby 2005.

[12] Ando Y, limura J, Arai S, et al. Risk factors for recurrent epistaxis: importance of initial treatment. Auris Nasus Larynx 2014;41(1):41-5.

[13] Kucik CJ, Clenney T. Management of epistaxis. Am Fam Physician 2005;71(2):305-11.

[14] Douglas R, Wormald PJ. Update on epistaxis. Curr Opin Otolaryngol Head Neck Surg 2007;15(3):180-3. 